\title{
Metformin for Lithium-induced Weight Gain: A Case Report
}

\author{
Samir Kumar Praharaj \\ Department of Psychiatry, Kasturba Medical College, Manipal, Karnataka, India
}

\begin{abstract}
Lithium is the first line treatment for maintenance treatment of bipolar disorder. Among the long term adverse effects, weight gain is likely to affect a subset of patients. There is no specific guideline for the treatment of lithium-induced weight gain. We report a young male with bipolar disorder who had significant weight gain with lithium $(25 \mathrm{~kg})$, which responded to metformin treatment at $500 \mathrm{mg}$ twice daily. The proposed mechanism of weight lowering effect of metformin includes changes in hypothalamic physiology, including leptin and insulin sensitivity, as well as circadian rhythm changes affecting food intake, regulation of fat oxidation and storage in liver, skeletal muscle, and adipose tissue.
\end{abstract}

KEY WORDS: Lithium; Metformin; Weight gain; Antimanic.

\section{INTRODUCTION}

Lithium is considered as the most effective maintenance treatment for bipolar disorder by virtue of mood stabilization, neuroprotective and antisuicidal properties. ${ }^{1)}$ There are several adverse effects associated with long-term lithium maintenance therapy. Among others, impairment in renal concentrating ability, hypothyroidism, increased calcium and cognitive adverse effects need monitoring. ${ }^{2)}$ Although not very common, weight gain is another adverse effect seen with chronic use of lithium. ${ }^{3-5)}$ An early study had found that lithium maintenance therapy stimulated weight gains of over $10 \mathrm{~kg}$ in $20 \%$, which was attributed to increased thirst in majority of individuals. ${ }^{6}$ In a recent meta-analysis, it was found that those receiving lithium had significantly more weight gain than the placebo group (odds ratio $1.89,95 \%$ confidence interval [CI] 1.27 to $2.82 ; p=0.002) .{ }^{2)}$ In a retrospective chart review, body weight gain with lithium treatment was 6.3 (standard deviation [SD] 9.0) kg, which was almost similar to that of sodium valproate $\left(6.4 \mathrm{~kg}\right.$, SD 9.0). ${ }^{7)}$ In comparison to lithium and valproate, weight gain with carbamazepine and oxcarbazepine is much lower. ${ }^{8,9)}$ The pharmacological

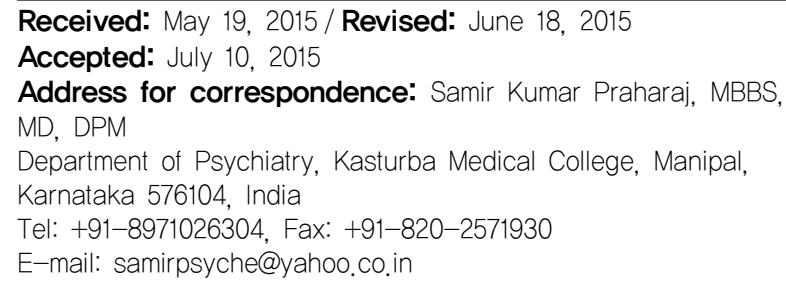

strategy for treatment of lithium-induced weight gain is not clear. We report a young male with bipolar disorder who had significant weight gain with lithium, which responded to metformin.

\section{CASE}

A 22-year-old male, height $173 \mathrm{~cm}$, presented with history suggestive of mania of 2 weeks duration. He had two prior episodes of mania that responded well to lithium, which he discontinued following remission of symptoms. His birth and developmental history was unremarkable and premorbidly he was well adjusted. There was no family history of any psychiatric illness. Physical and neurological examination was normal. Mental status showed features supportive of euphoric mania. Baseline investigations including blood count, thyroid profile, fasting and post prandial plasma glucose, lipid profile, liver and renal function test were normal. Considering past response, he was prescribed lithium carbonate $1,200 \mathrm{mg} /$ day (with serum level of $1 \mathrm{meq} / \mathrm{L}$ ) and quetiapine $400 \mathrm{mg} /$ day with which there was complete resolution of manic symptoms over next two months. Thereafter, quetiapine was gradually tapered over next six months.

After nine months, he reported of weight gain of $12 \mathrm{~kg}$ from his baseline weight of $68 \mathrm{~kg}$ (body mass index [BMI] $22.72 \mathrm{~kg} / \mathrm{m}^{2}$ ), while on maintenance dose of lithium 1,200 $\mathrm{mg}$ /day. He was suggested diet control and physical exercise (no formal program), and was maintaining well for next two years, after which he reported further weight gain

(c) This is an Open-Access article distributed under the terms of the Creative Commons Attribution Non-Commercial License (http://creativecommons.org/licenses/by-nc/4.0) which permits unrestricted non-commercial use, distribution, and reproduction in any medium, provided the original work is properly cited. 


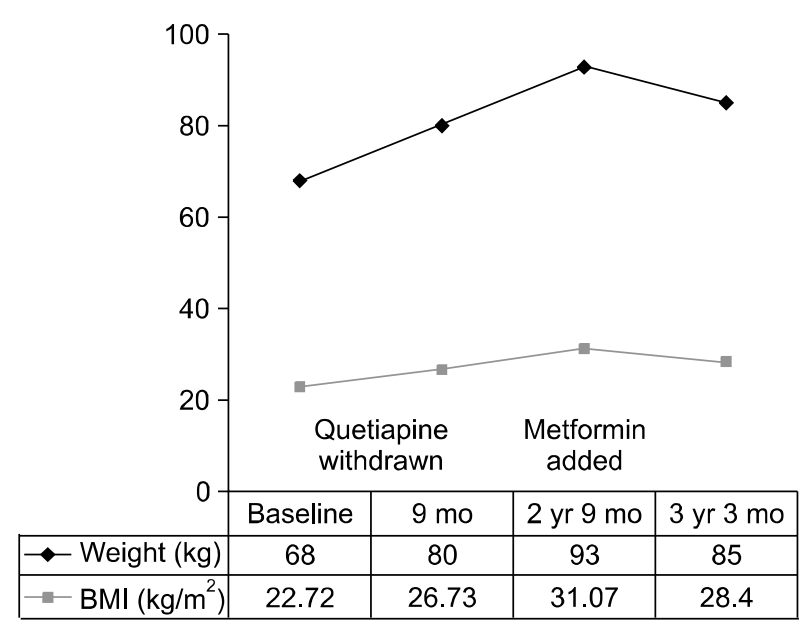

Fig. 1. Changes in body weight and body mass index (BMI)

of $13 \mathrm{~kg}$ (i.e., $93 \mathrm{~kg}$, BMI $31.07 \mathrm{~kg} / \mathrm{m}^{2}$, class I obesity). Investigations including blood sugar, lipid profile and thyroid functions were within normal range. Considering previous good response, lithium treatment was continued at the same dosage. He was started on metformin $500 \mathrm{mg}$ daily which was increased to $500 \mathrm{mg}$ twice daily for weight gain related to lithium. After six months, there was reduction of $8 \mathrm{~kg}$ (i.e., body weight of $85 \mathrm{~kg}$ ), without any emergent adverse effect. The changes in body weight and BMI are summarized in Figure 1. Fasting blood sugar was monitored during follow ups, which was within normal range.

\section{DISCUSSION}

Our patient gained $25 \mathrm{~kg}$ over three years while on lithium maintenance therapy for bipolar disorder. Although he was receiving quetiapine along with lithium in the initial two months, it was tapered off and the weight gain occurred while on lithium monotherapy. In absence of any other cause, it appears that weight gain is related to lithium. On Naranjo adverse drug reaction probability scale, score was 7 , which is suggestive of probable association. ${ }^{10)}$ It has been suggested that lithium-induced weight gain is a dose-dependent effect seen over serum concentrations more than $0.8 \mathrm{mmol} / \mathrm{L}$, ${ }^{5}$ and our case had a serum level of $1 \mathrm{meq} / \mathrm{L}$. Lithium is considered as one of the medication that is least likely to cause weight gain, in comparison with other mood stabilizers. ${ }^{1)}$ It is possible that, lithium causes weight gain in only a subset of patients, those having existing vulnerability. ${ }^{11)}$ Mechanisms of lithium-induced weight gain include insulin-like actions on carbohydrate and fat metabolism, polydipsia, and sodium retention. ${ }^{3)}$ In another study, changes in serum leptin levels are implicated for lithium-induced weight gain. ${ }^{12)}$ In animal models, it was found that lithium acts like nonspecific stress to increase weight gain by raising glucocorticoid levels. ${ }^{13)}$

Treatment of lithium-induced weight gain includes non-pharmacological measures such as exercise, avoidance of liquid calories and restricted calorie intake, ${ }^{14)}$ as well as several medications that have been useful for psychotropic-induced weight gain. ${ }^{15)}$ There are no specific guidelines for treatment of lithium-induced weight gain. Metformin has been found to be effective for weight gain associated with antipsychotics in non-diabetic patients. ${ }^{16-18)}$ For olanzapine-induced weight gain, weighted mean difference for body weight was 5.02 (95\% CI 3.93 to 6.10) $\mathrm{kg}$ lower with metformin as compared with placebo at 12 weeks. ${ }^{18)}$ Metformin has been also found to reduce body weight and BMI at a dose of 1,000-2,000 mg/day for 6-12 months in obese nondiabetic children and adolescents, as shown by a systemic review of 11 trials. ${ }^{19)}$ Similar findings were observed with the use of metformin in nondiabetic obese adults. ${ }^{20)}$ Moreover, there is no known clinically relevant pharmacokinetic drug interaction of lithium with metformin; lithium is rarely associated with development of hyperglycemia, which is countered by metformin. ${ }^{21)}$ Based on these data, metformin was considered for the treatment of weight gain associated with lithium. Our patient responded to metformin therapy with significant weight reduction $(8 \mathrm{~kg})$ over six months, and was tolerated well. The weight-reducing mechanism of metformin is possibly multifactorial, involving changes in hypothalamic physiology, including leptin and insulin sensitivity, as well as circadian rhythm changes affecting food intake, regulation of fat oxidation and storage in liver, skeletal muscle, and adipose tissue. ${ }^{22)}$ There are no systematic studies examining the efficacy of metformin for lithium-induced weight gain. Studies need to examine the role of metformin for the treatment of lithium-induced weight gain in randomized controlled trials.

\section{REFERENCES}

1. Coryell W. Maintenance treatment in bipolar disorder: a reassessment of lithium as the first choice. Bipolar Disord 2009;11 Suppl 2:77-83.

2. McKnight RF, Adida M, Budge K, Stockton S, Goodwin GM, Geddes JR. Lithium toxicity profile: a systematic review and meta-analysis. Lancet 2012;379:721-728.

3. Garland EJ, Remick RA, Zis AP. Weight gain with antidepressants and lithium. J Clin Psychopharmacol 1988;8:323330.

4. Baptista T, Teneud L, Contreras Q, Alastre T, Burguera JL, de Burguera $\mathrm{M}$, et al. Lithium and body weight gain. Pharmacopsychiatry 1995;28:35-44.

5. Torrent C, Amann B, Sánchez-Moreno J, Colom F, Reinares 
M, Comes M, et al. Weight gain in bipolar disorder: pharmacological treatment as a contributing factor. Acta Psychiatr Scand 2008;118:4-18.

6. Vendsborg PB, Bech P, Rafaelsen OJ. Lithium treatment and weight gain. Acta Psychiatr Scand 1976;53:139-147.

7. Chengappa KN, Chalasani L, Brar JS, Parepally H, Houck $\mathrm{P}$, Levine J. Changes in body weight and body mass index among psychiatric patients receiving lithium, valproate, or topiramate: an open-label, nonrandomized chart review. Clin Ther 2002;24:1576-1584.

8. Coxhead N, Silverstone T, Cookson J. Carbamazepine versus lithium in the prophylaxis of bipolar affective disorder. Acta Psychiatr Scand 1992;85:114-118.

9. Hasnain M, Vieweg WV. Weight considerations in psychotropic drug prescribing and switching. Postgrad Med 2013, 125:117-129.

10. Naranjo CA, Busto U, Sellers EM, Sandor P, Ruiz I, Roberts $\mathrm{EA}$, et al. A method for estimating the probability of adverse drug reactions. Clin Pharmacol Ther 1981;30:239-245.

11. Vendsborg PB, Bach-Mortensen N, Rafaelsen OJ. Fat cell number and weight gain in lithium treated patients. Acta Psychiatr Scand 1976;53:355-359.

12. Atmaca M, Kuloglu M, Tezcan E, Ustundag B. Weight gain and serum leptin levels in patients on lithium treatment. Neuropsychobiology 2002;46:67-69.

13. Levine S, Saltzman A. Lithium increases body weight of rats: relation to thymolysis. Prog Neuropsychopharmacol Biol Psychiatry 2006;30:155-158.

14. Dempsey M, Dunner DL, Fieve RR, Farkas T, Wong J.
Treatement of excessive weight gain in patients taking lithium. Am J Psychiatry 1976;133:1082-1084.

15. Gracious BL, Meyer AE. Psychotropic-induced weight gain and potential pharmacologic treatment strategies. Psychiatry (Edgmont) 2005;2:36-42.

16. Maayan L, Vakhrusheva J, Correll CU. Effectiveness of medications used to attenuate antipsychotic-related weight gain and metabolic abnormalities: a systematic review and meta-analysis. Neuropsychopharmacology 2010;35:1520-1530.

17. Björkhem-Bergman L, Asplund AB, Lindh JD. Metformin for weight reduction in non-diabetic patients on antipsychotic drugs: a systematic review and meta-analysis. J Psychopharmacol 2011;25:299-305.

18. Praharaj SK, Jana AK, Goyal N, Sinha VK. Metformin for olanzapine-induced weight gain: a systematic review and meta-analysis. Br J Clin Pharmacol 2011;71:377-382.

19. Brufani C, Crinò A, Fintini D, Patera PI, Cappa M, Manco M. Systematic review of metformin use in obese nondiabetic children and adolescents. Horm Res Paediatr 2013;80:78-85.

20. Desilets AR, Dhakal-Karki S, Dunican KC. Role of metformin for weight management in patients without type 2 diabetes. Ann Pharmacother 2008;42:817-826.

21. Baxter K. Stockley's drug interactions: A source book of interactions, their mechanisms, clinical importance and management. 9th ed. London:Pharmaceutical Press;2010.

22. Malin SK, Kashyap SR. Effects of metformin on weight loss: potential mechanisms. Curr Opin Endocrinol Diabetes Obes 2014;21:323-329. 